\title{
Flap casting of turbine engine optimization by numerical simulation
}

\author{
Marek Brůna ${ }^{1, *}$, Anna Remišová ${ }^{1}$ \\ ${ }^{1}$ University of Žilina, Faculty of Engineering, Department of technological engineering, Univerzitná \\ 1, 01026 Žilina, Slovakia
}

\begin{abstract}
Submitted article focuses on possibilities of increasing internal quality of flap casting of turbine engine produced by investment casting technology. Material porosity will be eliminated by altering the gate system. ProCast software has been used to evaluate and analyse the design of the flap. The aim of the research was to evaluate the porosity of the cast after its solidification, the flow velocity of the melted material and visualise the turbulence of the flow during casting. Main aim will be to observe and analyse velocity, flow, turbulences, solidification and internal porosity for nickel based alloy.
\end{abstract}

Keywords: Numerical simulation, investment casting, porosity

\section{Introduction}

The ever-increasing demands of customers, together with the industrial advancement of production, force the founders to improve the quality of the castings while reducing the price. Casting production by investment casting method is one of the most advanced production technologies currently used for production of castings with very high demands on quality, especially used in the aircraft industry or precision mechanics.

This technology makes it possible to create components whose production by other technology would be too expensive or impossible. [1,2]

Despite many positive attributes, defects can occur on castings, leading to economic losses and losses in quality. One solution to effectively avoid casting errors during the design process is to analyze the cause of the problem and to solve its removal. This work is focused on such a case. The working environment of the ProCAST simulation software was used to solve the porosity occurrence during the casting solidification, with subsequent application of the right solution.

Shrinkage formation involves heat flow, mass flow and some other complicated phenomena, a generally accepted practice to simulate shrinkage porosity is purely from thermal calculations. Through this simplest way, shrinkage can be recognized in terms of solidification patterns. It is defined that shrinkage appears in a spot within the closed loops formed by the isochronal contours of solidification time. This means a complete separation

\footnotetext{
* Corresponding author: rapture.marko@gmail.com

Reviewers: Eva Tillová, Ladislav Écsi
} 
of the casting from the riser, simultaneously, accompanied by the disappearance of the feeding path

\section{Experimental part}

The main objective of the work was to design solutions to improve the internal quality of the turbine engine flap. The casting is manufactured by the investment casting technology by the company CPP s.r.o., whose initially designed casting exhibited unacceptable internal defects. For this reason, the company asked for a solution to this problem. Analysis and design of possible solutions were carried out in the ProCAST simulation program.

\subsection{Characteristics of turbine engine flap}

The flap is a part of the so-called double flapper check valve (Figure 1) of the Trent 7000 turbine engine, designed by Rolls-Royce, developed for the Airbus A330neo.
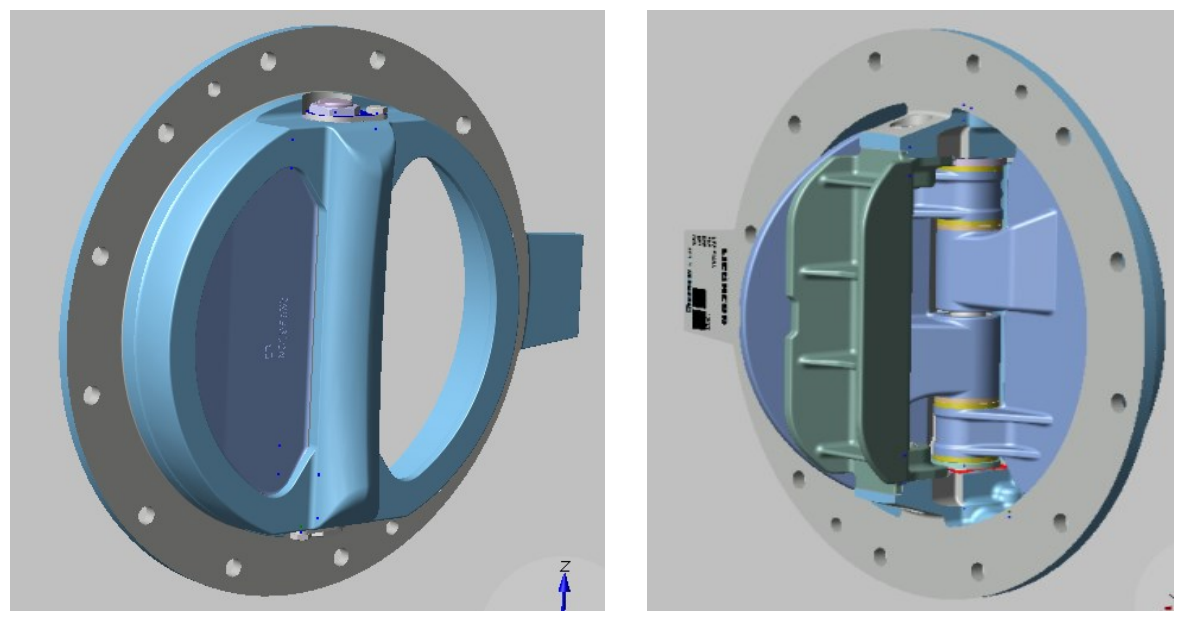

Fig. 1. Scheme of complete double flapper check valve with flap

Pumpage is a phenomenon that occurs when the air flow is disturbed by the engine, resulting in a reduction in the absolute flow rate of the airflow and the change in the rise angle of the flow on the blades. This causes the overpressure before the compressor and not beyond it, then gases from the combustion chamber expands to the front of the engine and loses the thrust. Rapid accelerating, respectively. Deceleration of the engine will result in an imbalance which has a negative effect on its life. Therefore, this phenomenon must be avoided by the check valves, which are opened when the pressure before the compressor reaches a critical value, after the pressure equalization, the flaps return to the original position. Placement of the flap as part of the valve is shown in Fig. 2. [3, 4] 


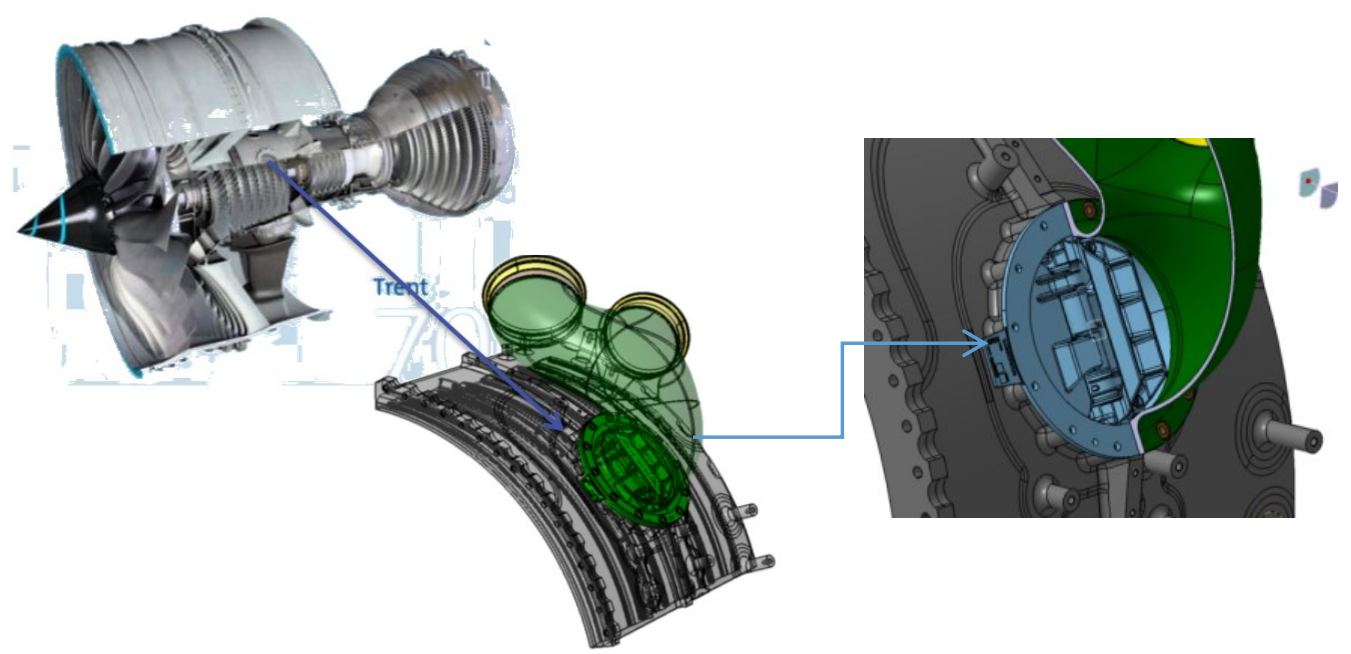

Fig. 2. Placement in the engine

The flap is made of INCONEL718. This material is classified among nickel super alloys and can be used up to temperatures of about $1050^{\circ} \mathrm{C}$. The microstructure of the material comprises an austenitic matrix (c) in which further secondary phases are dissolved. The Inconel 718 is highly heat-treated with the ability to obtain high mechanical properties, in particular hardness and strength, with a high degree of resistance to corrosion and is suitable for working in aggressive environments.

\subsection{Flap casting}

The first design of castings exhibited internal porosity at the points of maximum flap force loading. Areas with excessive porosity are located at the sections A-A and B-B shown in Fig. 3. The first design of tree with a castings prepared in software Solidworks is shown in Fig. 4.
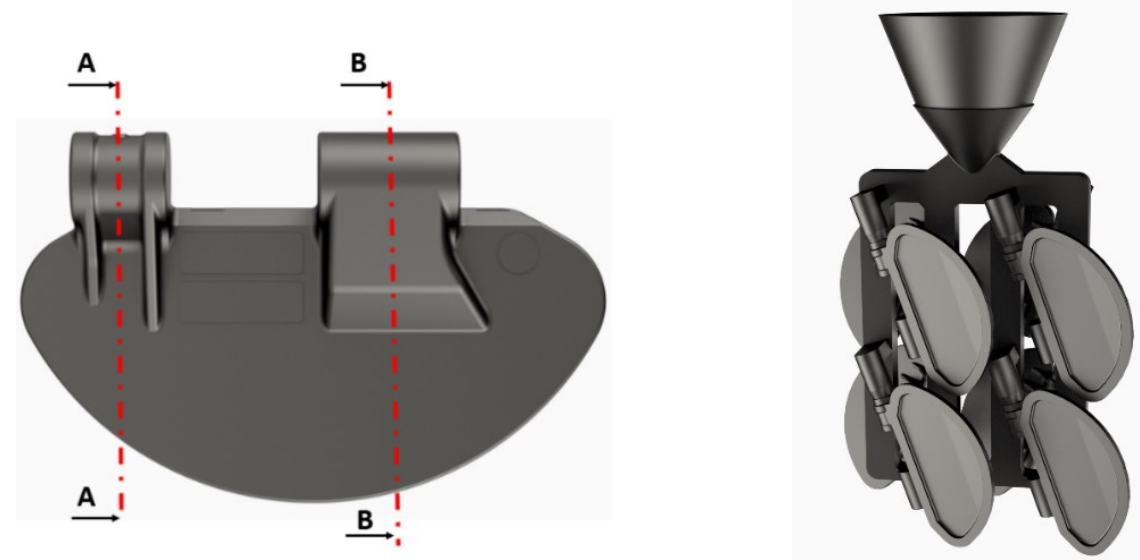

Fig. 3. Evaluated sections

Fig. 4. First design of the tree and castings 


\section{Evaluation of section A-A}

In section A-A, the porosity was evaluated using the brushed cuts (Figure 5 - left). The pore area represented $1.23 \%$ of the given area, which is supercritical for the customer. The rating scale set in ProCAST was 1\%. The simulation result confirmed the porosity at critical point and evaluated it approximately in the same range (more than 1\%). The critical area is shown in red in the simulation result (Figure 5 - right).

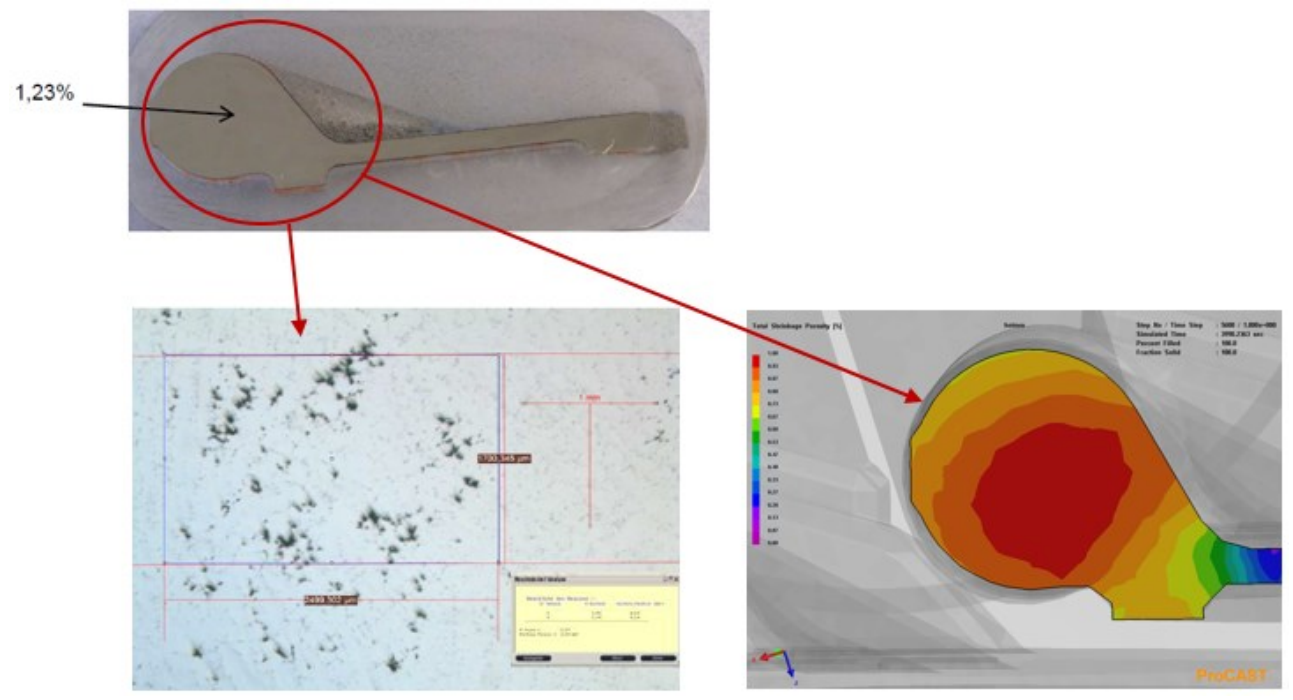

Fig. 5. A-A section cut with microstructure image - left; calculated porosity by ProCAST - right

\section{Evaluation of section B-B}

The same analysis was performed at B-B cut. The porosity detected at the cut was $3.04 \%$ (Figure 6 - left). The simulation again confirmed an identical critical area (Figure 6 - right). The resulting simulation image also shows a part of the gating system.

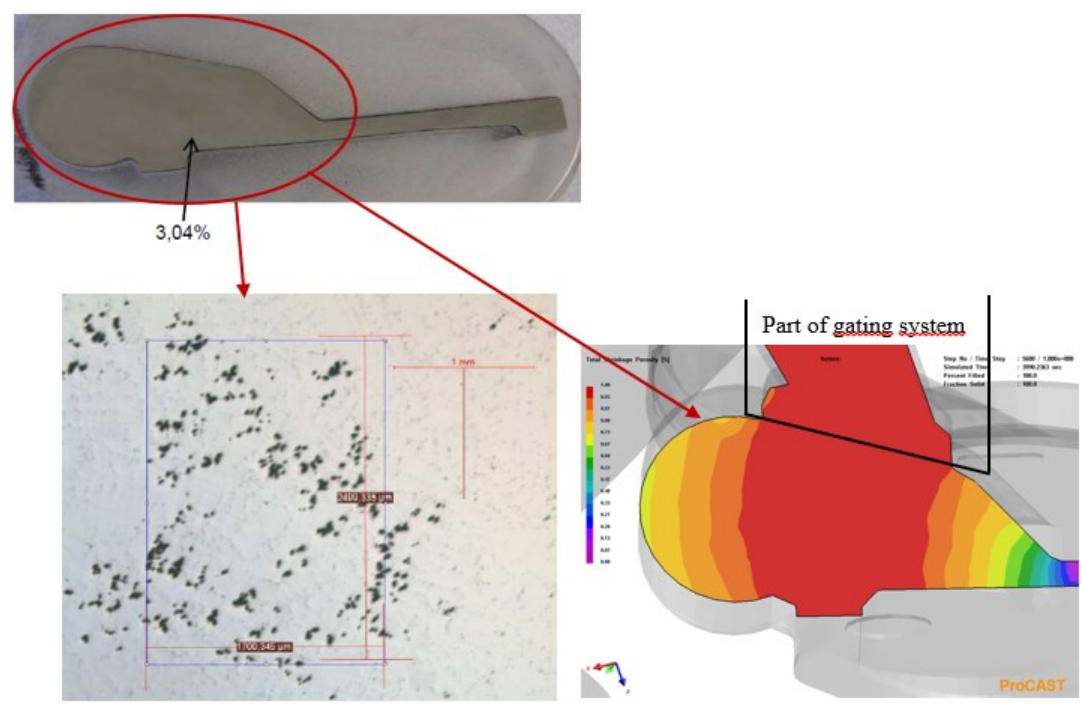

Fig. 6. B - B section cut with microstructure image - left; calculated porosity by ProCAST - right 


\subsubsection{Analysis and suggested solutions}

Due to the requirements of the customer, it was not possible to interfere with changes in the technological parameters of the casting (shown in Table 1). Elimination of the problem was therefore focused on the design changes of the tree (gating system and casting orientation). The analysis of the problem was focused on monitoring the solidification, the occurrence of hot spots and the monitoring of turbulence in the system. The input parameters entered into the ProCAST system are identical to the real parameters.

Table 1. Technological parameters

\begin{tabular}{|c|c|}
\hline Casting & $\begin{array}{l}\text { Vacuum furnace: - pouring temperature: } 1440 \pm 5^{\circ} \mathrm{C} \\
\text { - Filling time: } 3 \mathrm{sec} \text {. } \\
\text { - Pouring height }=500 \mathrm{~mm} \\
\text { - crucible type: silica } 5009 \\
\text { Material: - Inconel } 718 \\
\text { - batch weight: } 13.4 \pm 0.2 \mathrm{~kg} \\
\text { - Cooling on air }\end{array}$ \\
\hline Shell mold & $\begin{array}{l}\text { - number of layers: } 8 \\
\text { - shell thickness: } 8-11 \mathrm{~mm} \\
\text { Shell composition: - first layer: slurry based on zircon-kobalt-alumina } \\
\text { - 2. layer: slurry based on zircon, covered by zircon } \\
\text { - 3. layer: slurry based on zircon, covered by mullit } \\
\text { - 4. - 8. layer: slurry based on mullit, covered by mulit } \\
\text { - soaked in mullit } \\
\text { Annealing of the shell: - temperature: } 1050^{\circ} \mathrm{C} \pm 10^{\circ} \mathrm{C} \\
\text { - time: } 2 \text { hrs. } 30 \text { min. }\end{array}$ \\
\hline
\end{tabular}

\section{Solidification analysis}

During the solidification, the heat transfer occurs when the mold dissipates heat from the liquid metal. The overall nature of the casting crystallization affects the rate of heat removal from the metal in a mold that is directly dependent on the physical and geometrical properties of the casting and mold. [5]

With the simulation, it was found that the condition of the directional solidification was respected in each design (Figure 7), but it is also necessary to keep the width of the twophase interval during the solidification extended for the purpose of filling the melt into the places where is the risk of shrinkage porosity. For this reason, a modification was proposed in the form of insulation (Figure 8). The proposed insulation was located on the front part of the flap in the area of the thinnest wall. The insulator also covered the critical parts of the flap. One insulation layer with a thickness of $13 \mathrm{~mm}$ was proposed. 

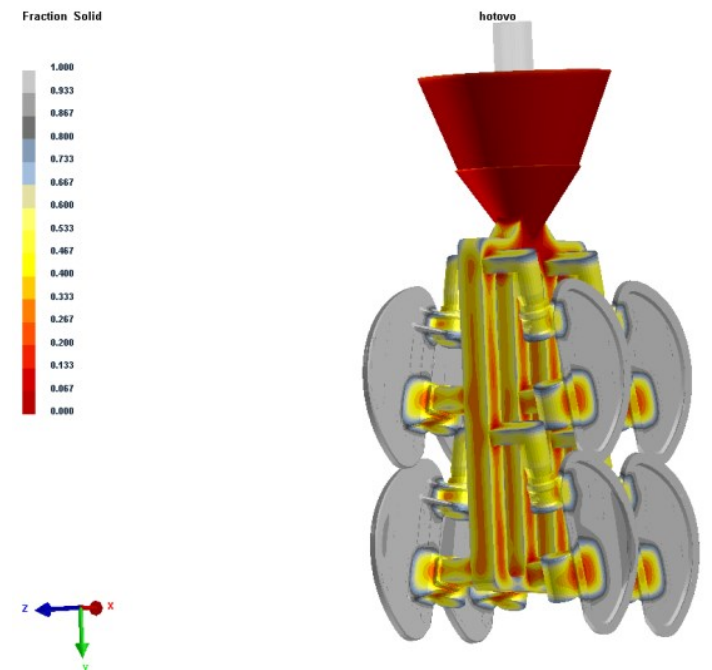

Fig. 7. Solidification result for first design

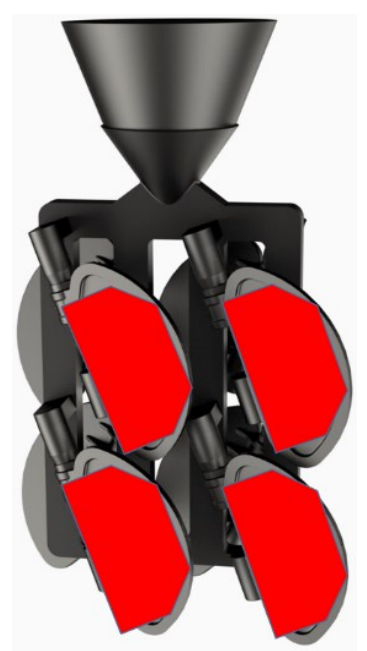

Fig. 8. Placement of the insulations

Solidification with an insulating wrap showed a decrease in porosity concentration in critical areas, confirming the simulation results of the porosity (Figure 9). However, solving the problem in this way was not sufficient as the porosity in the area B-B was still supercritical.
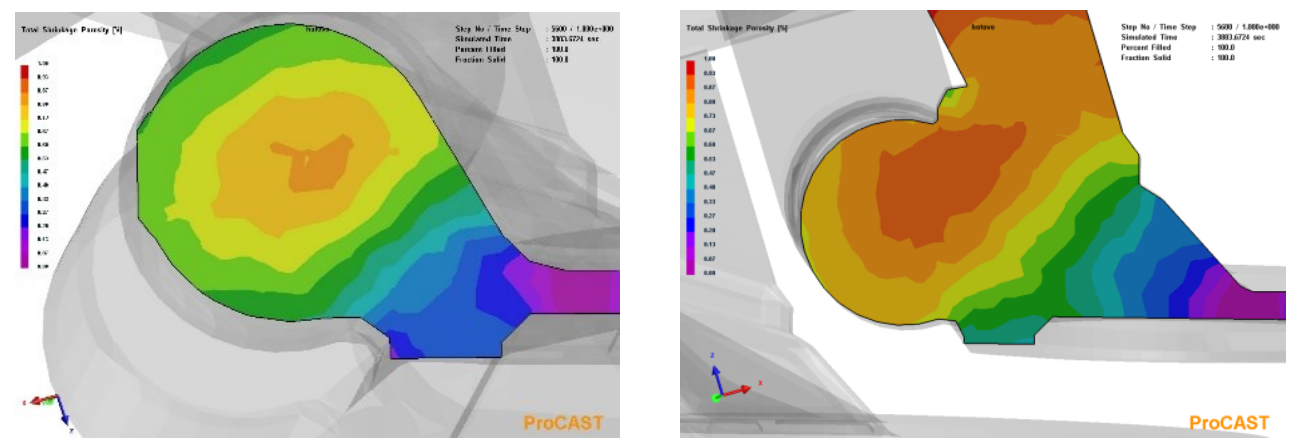

Fig. 9. Results for porosity occurence after insulation application

\section{Metal turbulence analysis}

The simulation result (Figure 10) analyzed the effect of metal turbulence. The filling process significantly influences the quality of the resulting casting, even in the case of casting in the vacuum. Although the rate of reoxidation is substantially reduced, the presence of oxides cannot be completely eliminated. For this reason, the nature of the flow is a very important factor because it influences the presence of oxides (bifilms). The individual flow paths determine the directional vector and, according to the indicated scale, are shown with color time spacing to analyze the flow pattern. Within the color spectrum, it can be concluded that the melt in the mold cavity is circulating undesirably and promotes the turbulent nature of the filling. Based on the assumption that the turbulence has an impact on the internal quality of the casts, a change of the gating system has been proposed. This change was centered on the creation of a single inlet channel, also with the change of the castings position. 


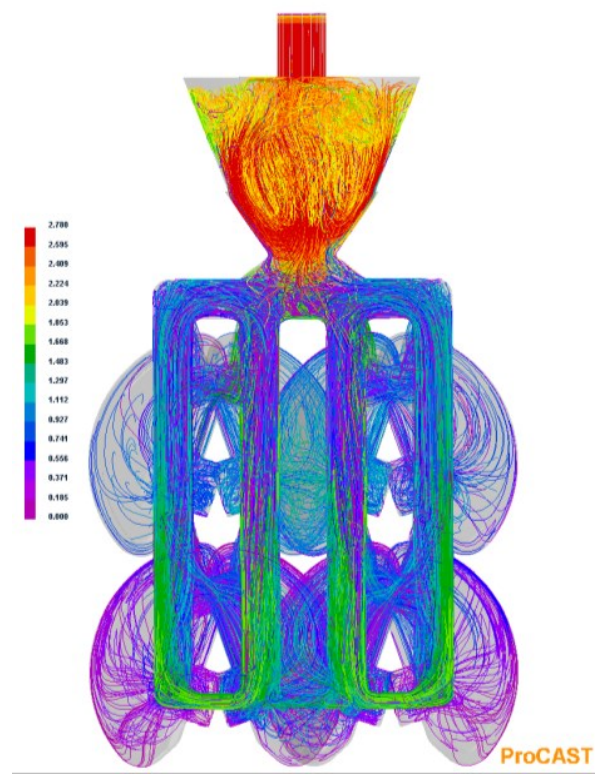

Fig. 10. Turbulence evaluation by ProCAST for the first design

Due to the positive effect of the tree's insulation, it was placed also on new design (Figure 11). Simulations for a new design focused on turbulences are shown in Figure 12.

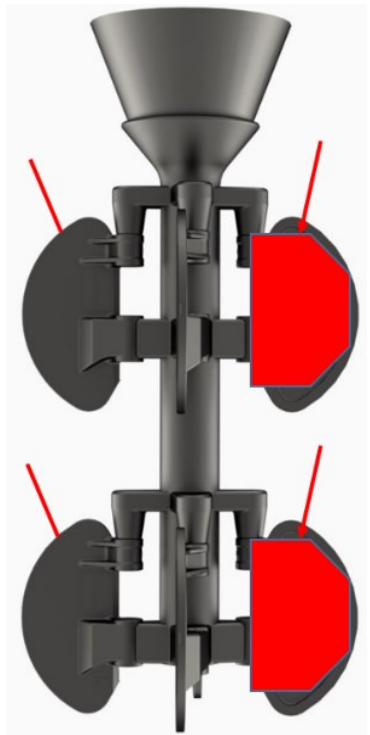

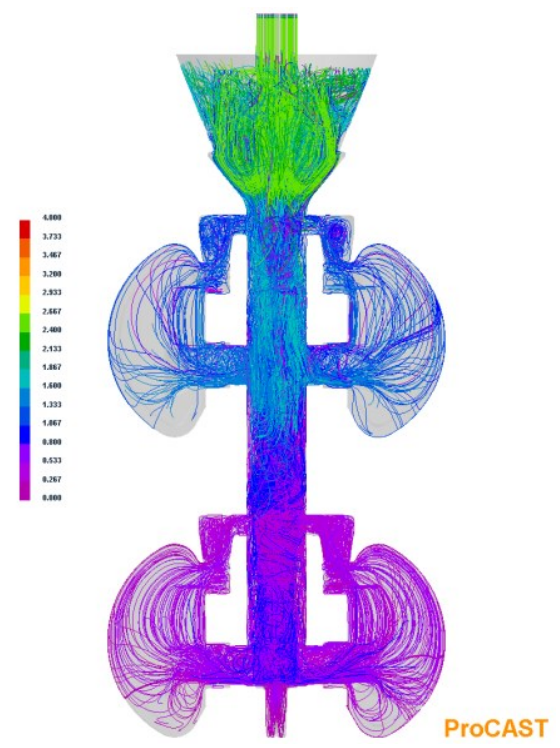

Fig. 11. Proposition of a new design Fig. 12. Turbulence evaluation by ProCAST for new design

The result of the turbulence evaluations shows a more direct flow of metal, which corresponds to the color spectrum of the individual vectors. The melt tends to fill the casting cavity and does not circulate in the inlet system. Subsequently, also result for solidification analysis was performed (Fig. 13). This variant also complied with the requirement for direct solidification. Based on the porosity analysis, the system has satisfactory results that do not show critical values in the monitored sections (Figure 14). 


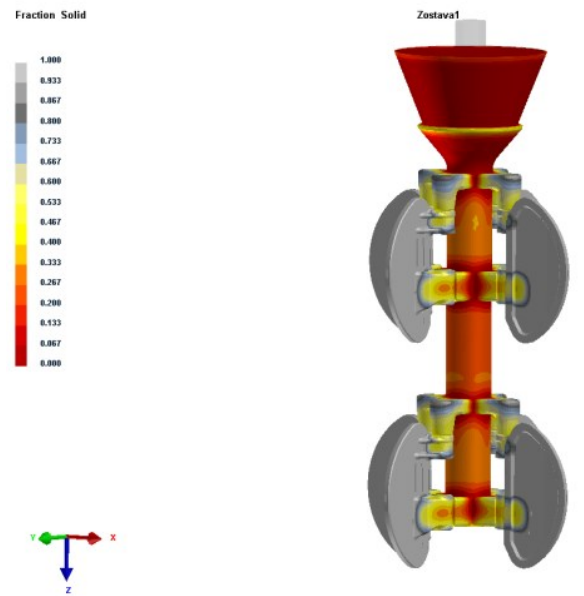

Fig. 13. Solidification evaluation by ProCAST for a new design

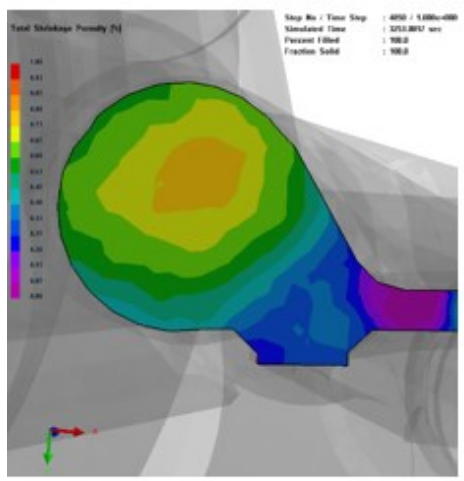

Section A-A

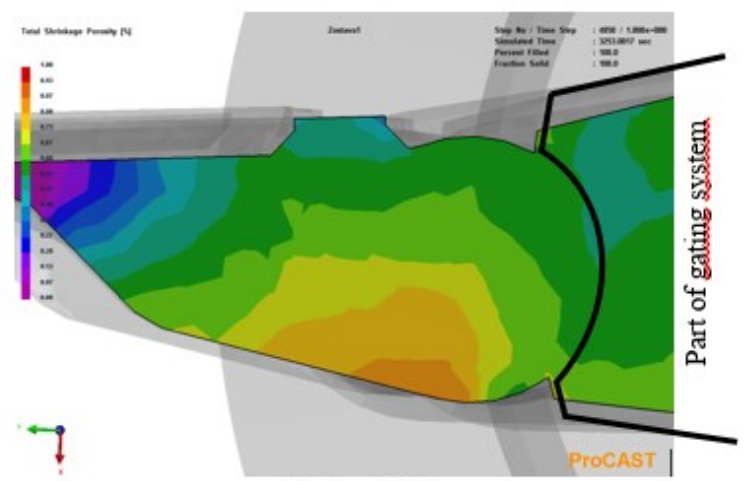

Section B-B

Fig. 14. Porosity evaluation by ProCAST for a new design

Based on the positive results of the ProCAST simulations evaluating the new design, along with the approval of this design by CPP s.r.o., it was processed and casted at the premises of the company (Figure 15).
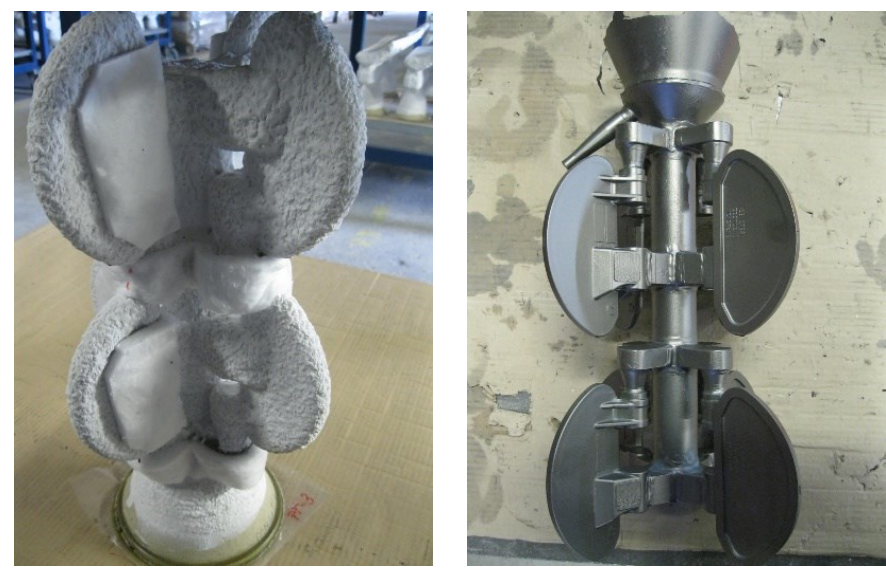

Fig. 15. Casting of a new design in company CPP s.r.o , shell mold - left, casting - right 


\section{Conclusion}

In this paper optimization of a flap casting process using the ProCast commercial code for casting numerical simulation has been carried out. Flow velocity and turbulence during casting and shrinkage porosity of the cast after its solidification have been evaluated. The weak parts of the original design causing the shrinkage porosity have been identified and the gate system and casting orientation of the double flapper check valve have eventually been altered to improve the design of the casting process. Finally, the calculated porosity has been compared with the experimentally determined porosity which confirmed the calculated results.

This work was created within the framework of the VEGA project grant no. 1/0494/17 with the title: The effect of remelting of recycled aluminum alloys on the properties of advanced castings in the automotive industry.

\section{References}

1. H. Fredriksson, U. Akerlind. Solidification and crystallization processing in metals and alloys. (Wiley, $1^{\text {st }}$ edition, 2012)

2. K. D. Carlson, C. Beckermann, Prediction of shrinkage pore volume fraction using dimensionless niyama criterion. Metallurgical and Materials Transactions A (40A), 163-175 (2009)

3. D. Bolibruchová, J. Macko, M. Bruna, Elimination of negative effect of fe in secondary alloys alsi6cu4 (en ac 45 000, a 319) by nickel. Archives of metallurgy and materials, ISSN 1733-3490, 717-721 (2014)

4. P. R. Beeley, R. F. Smart. Investment Casting. (The Institute of Materials, $2^{\text {nd }}$ edition, 1995)

5. D. Z. Li, J. Campbell, Y. Y. Li, Filling system for investment cast ni-base turbine blades. Journal of Material Processing Technology 148, 310-316 (2004) 